\title{
The P-TRAP project: Tackling the diffuse phosphorus input to surface waters
}

\author{
THILO BEHRENDS ${ }^{1}$, STEFAN PEIFFER ${ }^{2}$ AND SYLVIA \\ WALTER $^{1}$
}

${ }^{1}$ Utrecht University

${ }^{2}$ Bayreuth Center for Ecology and Environmental Research, University of Bayreuth

Presenting Author: t.behrends@uu.nl

In March 2019 the EU Marie Sklodowska-Curie Innovative Training Network P-TRAP has started. P-TRAP aims to develop new methods and approaches to trap phosphorus $(\mathrm{P})$ in drained agricultural areas and in the sediments of eutrophic lakes. The project has a dual objective: 1) to reduce the loading of surface waters with $\mathrm{P}$, which is the main cause for eutrophication and presents a key challenge in meeting the objectives of the EU Water Framework Directive; 2) to contribute to closing the agricultural $\mathrm{P}$ cycle by converting the trapped $\mathrm{P}$ into useful products for agricultural applications. The consortium consists of nine beneficiaries and seven partner organization, and is involving $11 \mathrm{PhD}$ students.

The various approaches to trap and recycle phosphorus (P) within the P-TRAP project have in common that they rely on the naturally strong connection between $\mathrm{P}$ and iron (Fe). This includes the high affinity of $\mathrm{P}$ for $\mathrm{Fe}$ (hydr)oxides but also the release and binding of $\mathrm{P}$ during the transformation of $\mathrm{Fe}$ minerals.

The structure of the P-TRAP project with the various work packages, related tasks and objectives will be explained. Examples of ongoing activities will be shown and highlights of first results will be presented. 